\title{
Determinants of Residential Location Decisions among the Pre-Elderly in Central Ohio
}

\author{
Hazel A. Morrow-Jones \\ Moon Jeong Kim \\ The Ohio State University ${ }^{a}$ The Ohio State University ${ }^{b}$
}

\begin{abstract}
This paper examines the differences and similarities in residential movement patterns and motivations among young households (respondents under the age of 50), pre-elderly households (age 50-64) and elderly households (age 65 and over) in Franklin County, the central county of the Columbus, Ohio metropolitan area. The patterns are mapped and the motivations and household characteristics are explored through descriptive analysis and discriminant analysis. Most expectations are supported and the pre-elderly are seen to be a distinct group with some similarities to each of the other two age cohorts, but also with some unique characteristics and interests.
\end{abstract}

Keywords: Residential Location; Pre-elderly; Discriminant analysis

\section{Introduction}

There is a long history of research on residential mobility based on the importance of accessibility in people's decisions. However, households often choose their homes and neighborhoods based on a variety of factors including preferences for larger and newer homes, the quality of schools and safety, rather than on accessibility issues such as the proximity of workplaces, friends and family, and retail centers (Kim and Morrow-Jones 2005; OHRN 1994). Accessibility measures are ranked as less important by most people (Kim and Morrow-Jones 2005; OHRN 1994) and several studies have shown negative utilities related to commuting time in residential location models (Levine 1998; Weisbrod et al. 1980). In addition, the life-course model of residential mobility suggests that different age groups with different household characteristics have different desires for their residences, and that these preferences change over the life course (Wenning 1995). So, even if one demographic group focuses on distance to work, others might not, and the group's own preferences might change with time (Masnick 2003). As the demographic structure of the U.S. population shifts, we should expect changes in reasons for residential mobility as well.

The baby boom cohort has had important effects on American life throughout its history. Now the baby boom is aging and entering a new life stage as its members prepare for retirement. Because this currently pre-elderly group will become a major portion of the elderly population in the near future, it is important to understand its members' current mobility and residential location decisions. Despite widespread acceptance of the life course model and its implications,

${ }^{a}$ morrow-jones.1@osu.edu

bkim.1678@osu.edu 
and the potential importance of this pre-elderly group in that model, research on the group's residential location decisions has not received much attention.

This paper explores patterns of repeat home buying and determinants of residential location decisions among the pre-elderly, focusing on intrametropolitan mobility using a survey of repeat home buyers in Franklin County, Ohio - the central county of the greater Columbus, Ohio metropolitan area.

In this research, it is assumed that pre-elderly people (aged 50-64), are still active in the job market and that most of their children have departed from their homes. Planning for retirement may have an effect on their decisions, and they may have begun to plan for some physical limitations as well. In addition, they are at the peak of their earning years and are less constrained by resources than other groups. All age groups probably have an interest in using their housing or neighborhood choices to indicate the status they have achieved, but the larger disposable incomes of the pre-elderly may give them more resources than the other age groups to accomplish this. These characteristics of the pre-elderly will affect their residential location decision patterns, and we expect to see that these patterns differ from those of the younger and older populations.

\section{Literature Review}

In the simplest form of the monocentric model developed by Alonso, Mills, and Muth, distance to the workplace is a primary determinant in households' residential location decisions, along with land rents (Alonso 1964; Mills 1967; Muth 1969). Early research using this model focused on density, residential rent gradients and commuting distances (for discussions of weaknesses, see Cropper and Gordon 1991; Hamilton and Röell 1982, among others). Several studies showed that utilities related to commuting time were negative in residential location models (Levine 1998; Weisbrod et al. 1980).

Another body of literature suggests that amenity features such as good schools and low crime rates are more important than distance to work and other accessibility factors such as public transit availability and commercial activity accessibility (Giuliano and Small 1993; Kim and Morrow-Jones 2005; OHRN 1994). According to the Ohio Housing Research Network (1994), the major reasons for mobility (based on actual movement decisions) in Ohio's seven largest metropolitan areas are school quality, neighborhood safety, property values, and the preference for a larger and newer home. Kim and Morrow-Jones used a survey of recent home buyers and found that a variety of considerations play a role in residential location decisions; these include housing characteristics (floor plan, quality of construction, and cost), community characteristics (safety of the neighborhood and good investment or resale value), and school quality (school reputation and quality of schools' academic programs). They found that distance to work was relatively unimportant. Krizek and Waddell (2003) addressed the possibility that different lifestyles may create different demands or different behaviors in the households' accessibility-related activities and residential location choices.

One explanation for the variety of reasons for moving found in different parts of the literature is that many authors assume that moving households are similar to each other and fundamentally want the same things. The life-course model, however, argues that at different stages of life, household characteristics and the roles that people take on can be expected to lead to different preferences about residences and places (Morrow-Jones and Wenning 2005). That is 
to say, residential location decisions need to be studied based on disaggregated datasets in order to understand the complexities of different households' decisions. For example, households with children and relatively higher incomes tend to live in suburbs, because of a need for larger houses, larger lots, and strong schools. This tendency is commonly accepted in research on suburbanization (Filion et al. 1999). Most research on the elderly has focused on the life-course model as it relates to the departure of children, retirement, widowhood, and other factors due to the specific characteristics of the age. Rowles (1993) noted that older people want to live closer to their children but still be independent in their residential location decisions.

While these differences between age groups are generally accepted, there has not been much research on the residential location decisions of the pre-elderly - the group who are nearly beyond the child rearing years and are planning for retirement, but who have not yet reached their elder years. A few authors have briefly noted that the mobility of the pre-elderly (those aged 55 to 64) tends to be stimulated by expected retirement rather than by work-force related reasons (Bures 1997; Clark et al. 1996), tying them more closely to the elderly cohort than to young families. Myers (2000), however, makes the point that all consumers of housing (especially new housing) must deal with a market that largely caters to the needs of family households with children.

In the twenty-first century, increases in the size of the elderly population will be important to the housing market. According to Walters (2002), 20 percent of the U.S. population will be 65 or older by 2030 . The mobility of the elderly is lower than that of younger age groups; however, there has been a recent increase in mobility in preparation for retirement.

The baby boom generation has affected the United States in many ways throughout its history. In addition, its members are (or at least like to think they are) redefining retirement and elderhood as they reach that stage of life (see for example Ezell's book aimed at baby boomers titled Retire Downtown, 2006). Morrow-Jones and Wenning (2005) argue that those who are currently pre-elderly may have different patterns of movement than previous elderly groups have had because this group of baby boomers has a different historical context and is more educated and wealthier than any cohort before them. They are accustomed to home ownership and mobility. Their moves as pre-elderly people may be in preparation for retirement, or they may simply reflect needs for this particular life stage, with additional moves planned as people age through later stages in life. Despite the potential importance of this group to housing markets, research has neglected their residential location decisions and how those decisions might differ from those of younger and older cohorts.

Pre-elderly people are defined here as those aged 50 to 64 . They may still be (and probably are) active in the job market, but retirement expectations may have started to affect their mobility decisions. Their children have already departed or begun to depart from their homes. They may recognize the need for a smaller or more age-friendly house, or they may have other priorities at this point. The house price itself may not be of much concern because they are at the peak of their earning years. However, their housing or neighborhood choices will indicate the lifestyle they have adopted during their current stage of life and the status that they have achieved. These characteristics of the pre-elderly cause their patterns of residential location to differ from those projected by generalized theories of residential location. 


\section{Hypotheses and Methodology}

\subsection{Hypotheses}

A key hypothesis of this research is that certain issues will be more or less important to different age groups of home buyers. A model with an emphasis on distance to work will have the best fit for the youngest group (those in which the respondent is under 50 years old). This group will be much more likely to have school-age children in their homes and will therefore be more concerned with school quality and reputation and with other factors that are believed to create good conditions for children, such as large houses and yards, little local traffic, safe neighborhoods, and neighbors with high economic status. Because home buyers in this group are almost certainly in the labor force, they will be concerned with the length and cost of their commutes as well as with traffic conditions. Most homeowners in this group will be in intact marriages and in many cases there will be two workers as well as children in the household. Thus both time and money will be constraints on their activities and they may look for residential locations near retail centers, recreational facilities, and family or friends to lower both the temporal and monetary costs of non-work activities.

As noted above, the residential mobility of the elderly has been studied, and this group is generally thought to look for less expensive housing since their incomes generally decline following retirement. Having no children in the household and a higher likelihood of being single, members of these households may look for smaller housing units. They may also be interested in being near services and family and friends, but they have fewer concerns with work location and commuting. They are concerned with safety, however, as the elderly may feel vulnerable as their physical health declines.

This research examines the hypothesis that the pre-elderly differ from the other two age groups in this study in their residential choices and in the reasons for those choices. This group was born between 1942 and 1956 (the survey was conducted in 2006), and while this does not exactly match the baby boom's birth years (generally considered to be roughly 1946 to 1964) it clearly represents the older part of the boom.

The pre-elderly group in this research is expected to have the highest income of all three groups, far fewer children at home than the youngest group, and a higher percentage of intact marriages than the oldest group. This means they will be supporting fewer people on higher incomes and thus have more disposable income than either of the other two groups. With no children at home, their time will also be subject to fewer constraints than the youngest home owners, and they will therefore have more freedom to do things they want to do, such as traveling or participating in other activities outside their homes. Relative to the oldest group, they should be physically more able to undertake a wide range of activities.

They will probably still be working and so will retain an interest in commuting distance and other accessibility factors (unlike the elderly), but will be somewhat less concerned with this factor than the youngest group. They will have relatively little focus on school quality except as it affects the investment value of their homes (and that will be quite important). With the possibility of less time spent at home, they may have stronger desires for newer or lowermaintenance homes than the other groups. This may or may not mean smaller homes, but may mean that, on average, the group finds smaller yards or easy-care landscaping more important. Because of its resources, this group will be able to make residential location choices that "say something" about their status and interests-though exactly what they want to say will vary 
from household to household within the group. The group's physical health should be better than that of the elderly, but perhaps not as good as the youngest group. They will also be aware of their aging and may try to find homes that are age-appropriate (single-floor houses, for example) and that will serve them well should they develop physical problems.

These hypotheses are aimed at describing the groups in general; of course, there will be exceptions within any cohort. To the extent that these expectations are borne out (and depending on the specific patterns that result), a variety of policy implications can be drawn and additional research may be called for.

\subsection{Data}

The data set used in this research is based on deed transfer records for properties sold between October 2004 and April 2006 (18 months). Every sale of property in Ohio requires the filing of a deed transfer form and these have been collated into computer-readable files. The forms list the names of both the buyers and the sellers, and these fields were used to create a dataset of households who sold one residential property and bought one residential property in the study area during the 18-month time period. These households were surveyed in summer and fall of 2006.

The survey was sent to a random sample of households in the database and produced approximately 500 usable surveys from Franklin County, a 22 percent return rate. Examination of the returns indicates that they are proportional to the population as far as communities where homes were sold, but that they slightly over represent the suburbs as a place to purchase a home. This may bias the survey somewhat in favor of household types that buy in suburbs and their particular reasons. We have no way of knowing about demographic biases in the survey returns.

The analysis begins by mapping movement patterns within Franklin County, focusing on the central county rather than the entire metropolitan area because the central area encompasses approximately 70 percent of all cases.

Respondents were asked about their reasons for selling their previous homes and their reasons for choosing their current homes. A list of possible reasons was supplied and respondents rated the importance of each reason on a seven-point Likert scale, with 1 indicating "very unimportant" and 7 indicating "very important." The main focus of this paper is reasons for choosing the current home. The survey also asked a variety of questions about the households' characteristics.

A total of 505 cases were analyzed. Households were divided into three groups depending on the age of the first adult listed as a member of the household: younger people (18-49 years old, inclusive), pre-elderly people ( $50-64$ years old, inclusive), and the elderly (65 years old and older). Of the respondents, 297 (58.81\%) were in the younger group, 131 (25.94\%) were preelderly, and 50 (9.90\%) were elderly; 27 respondents (5.35\%) did not give their ages and were removed from the analysis. The analyses were weighted to reflect sampling differences between communities in the study area and some additional cases were removed from certain analyses due to failure to respond to some questions ${ }^{1}$.

Variables describing the households were collected in categorical form and some were used in the analysis as dummy variables. If the education level (Higher Education) of the first adult

\footnotetext{
${ }^{1}$ The proportion of homes actually purchased in the communities was used to weight the survey responses so that the survey proportions matched the proportion purchased.
} 
listed in the survey (assumed to be the respondent) is more than 16 years (B.A. level) the education variable is defined as 1 , and if not it is defined as 0 . Income is a categorical variable from $\$ 20,000$ to more than $\$ 200,001$, with a span of $\$ 20,000$ in each category. If the respondent is white the variable Race is defined as 1 , and if not it is defined as 0 . If the respondent is married the variable Married is defined as 1, and if not (e.g., single, separated, widowed or divorced) it is defined as 0 . If the respondent is widowed, the variable Widowed takes the value of 1 and it takes the value of 0 otherwise. Lastly, if there are children under 18 years old in the household the variable Presence of Children equals 1 , and if not it is defined as 0 .

\subsection{Methodology}

In order to map the spatial distribution of the pre-elderly's residential destinations, we geocoded 502 of the 505 deed transfer records and linked them to the repeat home buyers' surveys for Franklin County. The preferred purchase locations by zIP code for the pre-elderly were mapped based on a weighted proportion of cases in the ZIP code. Figure 1 represents the proportion of all pre-elderly households choosing each zIP code in the sample. Figure 2 shows pre-elderly households as a proportion of all the households choosing the particular ZIP code.

The next section presents the results of tests for significant differences in variable averages between the pre-elderly and the other two groups. Most of the variables are in ordinal form; however, the means and standard deviations still provide useful summary information to support comparison of the groups. Because these univariate comparisons do not control for any other variables, discriminant analysis is used to explore the extent to which different decision factors distinguish between the three age groups of home buyers holding other things constant. The variables used include household characteristics and the importance of reasons for choosing the location purchased.

\section{Results}

\subsection{Descriptive Results}

\section{Spatial Concentrations}

Figure 1 shows the proportion of all pre-elderly households choosing each ZIP code. The darker the color on the map, the more highly preferred it is by pre-elderly people. Table 1 provides information on communities mentioned specifically in the discussion. As can be seen on the map, the focus population generally prefers areas in relatively suburban locations. The zIP code located on the northwest side of Franklin County (43017) attracts a large number of pre-elderly home buyers. Most of the area is within the boundaries of the city of Dublin, one of the most attractive newer suburbs in the region, with characteristics including high median household income, a moderate property tax rate, very good school performance, many employers in and near the suburb (it is located on the outer belt highway), relatively high traffic congestion, and newly developed suburban neighborhoods.

Another popular ZIP code (43026) for the pre-elderly is located on the west side of Franklin County. Most of these homes are within the municipal boundaries of the City of Columbus, which is the central city of the metropolitan area, even though the zIP code is relatively far from the center of the city. However, the units are all located in the Hilliard City Public School District (moderate school quality) not the Columbus Public School District. A third zip code 
Table 1: Community characteristics

\begin{tabular}{|c|c|c|c|}
\hline & $\begin{array}{l}\text { Median Household } \\
\text { Income (1999) }\end{array}$ & $\begin{array}{c}\text { Real Property } \\
\text { Tax Rate }(2005)^{b}\end{array}$ & $\begin{array}{l}\text { School Performance } \\
\text { Index Score }(2005)^{c}\end{array}$ \\
\hline $\begin{array}{l}\text { Dublin } \\
\text { (Dublin City SD) }\end{array}$ & $\$ 91,162$ & 101.11 & 101.6 \\
\hline $\begin{array}{l}\text { Hilliard } \\
\text { (Hilliard City SD) }\end{array}$ & $\$ 69,015$ & 114.61 & 97.2 \\
\hline $\begin{array}{l}\text { Grove City } \\
\text { (Southwestern City SD) }\end{array}$ & $\$ 52,064$ & 98.06 & 88.0 \\
\hline $\begin{array}{l}\text { Columbus } \\
\text { (Columbus City SD) }\end{array}$ & $\$ 37,897$ & 91.03 & 73.7 \\
\hline (Licking Heights Local SD) & & $\mathrm{N} / \mathrm{A}^{\mathrm{d}}$ & 89.8 \\
\hline \multicolumn{4}{|c|}{$\begin{array}{l}\text { a Data from the U.S. Census Bureau. } \\
\text { b Real property (residential and agricultural) tax data based on gross millage. The data were obtained } \\
\text { from Tax Data Series: All Property Taxes provided by Ohio Department of Taxation (http://tax. } \\
\text { ohio.gov/channels/other/research.stm). } \\
\text { "The school performance index score is a "weighted average of test scores across all levels and topics" } \\
\text { from the interactive Report Card Home (ILRC) provided by the State of Ohio's Department of } \\
\text { Education (http://www.ode.state.oh.us). } \\
\text { d This district crosses corporate and unincorporated area boundaries, so it was not possible to cal- } \\
\text { culate the tax rate. }\end{array}$} \\
\hline
\end{tabular}

(43123) preferred by the pre-elderly is located in the southwest of the county and most of the area is within the boundaries of Grove City and the Southwestern Public School District, a weaker school district but a relatively low tax area. These three zIP codes show a high proportion of the pre-elderly, but we should note that the zIP codes are preferred by the other two age groups as well. The first two zIP codes are also popular with younger households and the last ZIP code with the elderly population.

Figure 2 shows the pre-elderly as a proportion of the total number of households buying in each zIP code. It indicates the location preference patterns of pre-elderly people compared to the other two groups. Figures 1 and 2 should be compared for a clearer analysis. Two ZIP codes (one in the northeast and one in the southwest of the county) had only one pre-elderly household and no households from the other groups, resulting in the high proportions of preelderly residents. Those zIP codes are ignored in the following discussion. In two ZIP codes (43213 and 43004) on the east side of Franklin County, the pre-elderly make up a relatively high proportion of the home buyers. Examining the exact locations of these units indicates that these people purchased within the municipal boundary of the City of Columbus, even though the ZIP codes appear to indicate suburban locations. The area is characterized by lower median household income and lower property tax rates, but also by safe and newly built neighborhoods. Some of these units are in the Columbus Public School District and others are in the Licking Heights Public School District. Both of these districts show weaker school performance test scores and school reputations. These areas would be attractive to home buyers without children.

A cluster of young and pre-elderly people in the center of the map (the light blue area just south of the central white ZIP codes) indicates new growth in the downtown housing market and in a gentrified neighborhood south of downtown Columbus. These areas are apparently 


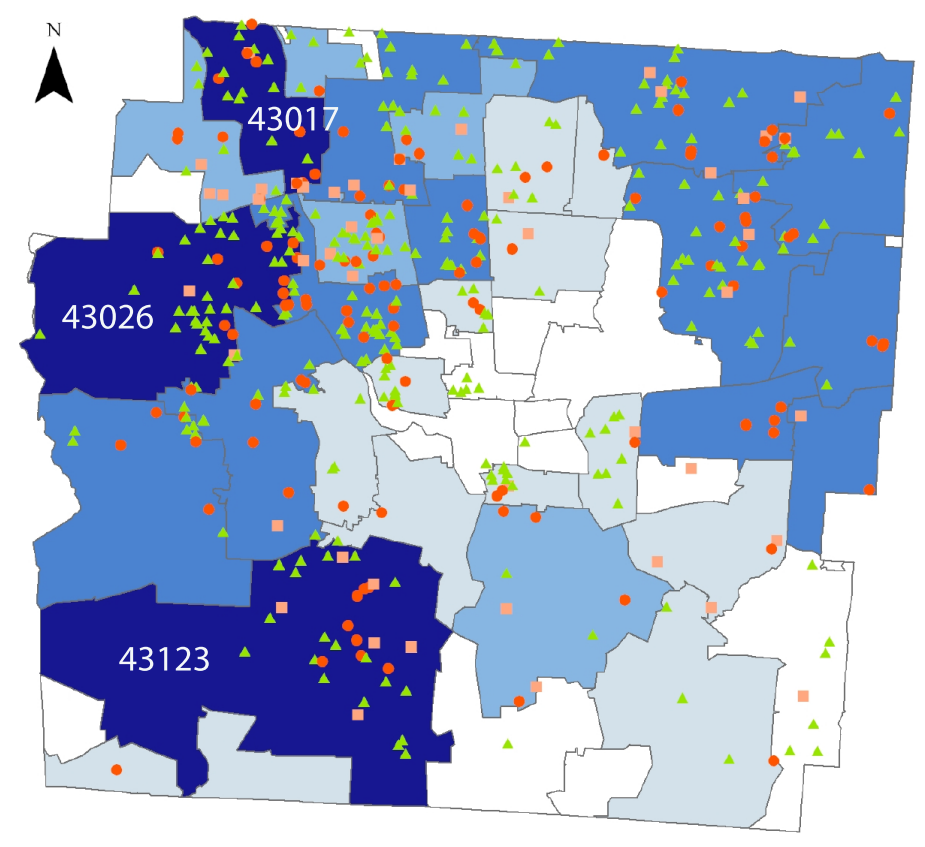

\section{Age Groups}

$\triangle \quad$ Younger People

- Pre-Elderly

- Elderly

Preferred Location

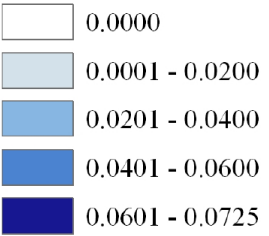

Figure 1: Proportion of pre-elderly households selecting ZIP code.

attracting some home buyers below the age of 65 , supporting the hypothesis that some members of the pre-elderly group move for lifestyle and status purposes, as these areas are expensive, highstatus neighborhoods for childless households. ${ }^{2}$

The data mapped in Figures 1 and 2 indicate that the pre-elderly appear to be attracted to neighborhoods characterized by low property tax rates but possessing suburban amenities such as safety and newly developed neighborhoods, with some preferring the high-status downtown locations. The quality of schools per se seems irrelevant, as both strong and weak districts attract the pre-elderly. The level of taxes may be important to pre-elderly subgroups with different income levels. Younger respondents tend to be attracted to areas with better school reputations and concomitant higher property taxes.

\subsection{Descriptive Statistics}

Table 2 shows the characteristics of the three different age groups in our survey. All three groups are overwhelmingly white (a minimum of nearly 90 percent among the elderly). As expected, the elderly are less likely to be married (46\%) and much more likely to be widowed (28\%) than either of the other two groups. The youngest group is the most likely to be married (over 81\%). Sixty-two percent of the pre-elderly are married and about four percent are widowed. Not surprisingly, almost two-thirds of the youngest respondents have children under 18 living in the

${ }^{2}$ Additional spatial analysis shows that most of the school districts with high reputation and performance were preferred by younger people, implying that they may be differentiated from clusters of younger people in downtown by the presence of children. 


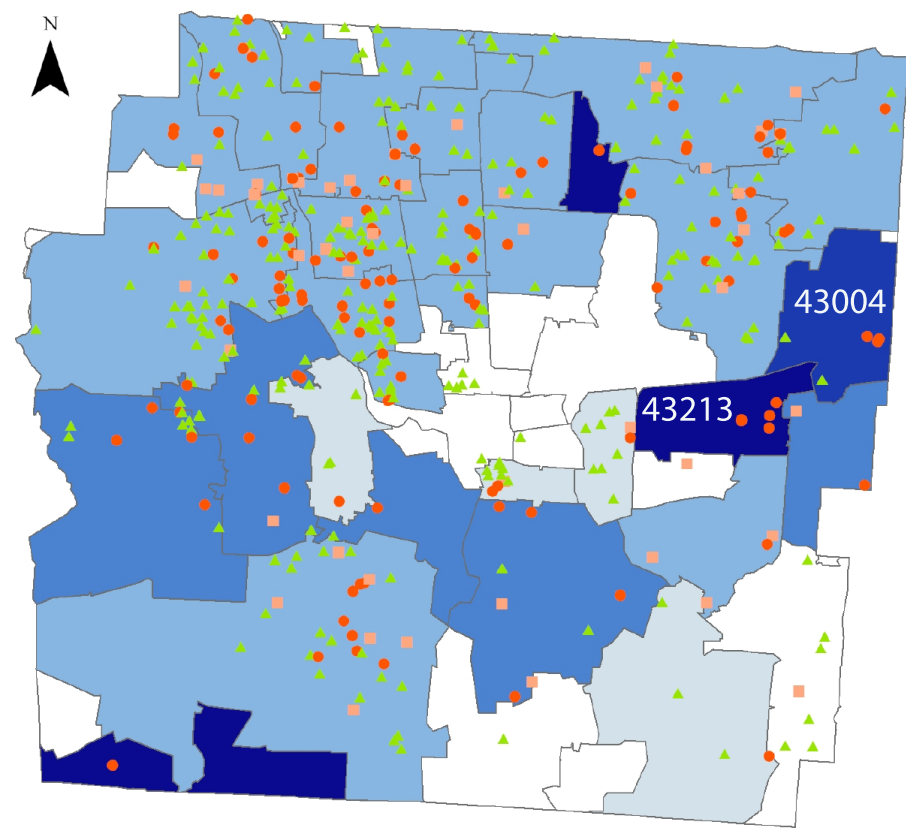

\section{Age Groups}

$4 \quad$ Younger Pcople

- Pre-Elderly

- Elderly

Pre-Elderly Proportion of All Households

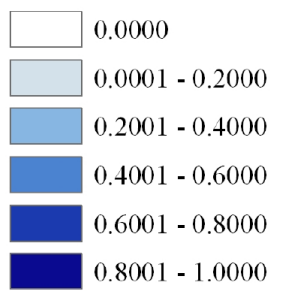

Figure 2: Pre-elderly as a proportion of all households moving to ZIP code.

household. Ten percent of the pre-elderly still have children of this age and none of the elderly do, again supporting initial expectations.

Table 2: Characteristics of the three age groups (percentages).

\begin{tabular}{lrrrrr}
\hline & White & Married & Widowed & $\begin{array}{r}\text { Presence of } \\
\text { Children }\end{array}$ & $\begin{array}{r}\text { Higher } \\
\text { Education }\end{array}$ \\
\hline Younger & 92.61 & 81.07 & 0.00 & 63.64 & 77.57 \\
Pre-Elderly & 94.23 & 61.50 & 4.04 & 10.42 & 63.00 \\
Elderly & 90.31 & 45.75 & 28.12 & 0.00 & 55.07 \\
\hline
\end{tabular}

Contrary to the initial hypothesis, the pre-elderly group does not have the largest proportion of college educated people among the three groups. Instead, the proportion with a college education is inversely related to the age of the cohort. The same is true for income, although the initial hypothesis of this research was that the pre-elderly would have the highest income. The average income of the youngest respondents is $\$ 97,800$; of the pre-elderly is $\$ 82,400$; and of the elderly is $\$ 40,600$. $^{3}$ A large part of the difference in income between the younger two groups may reflect the differences in the number of adults in the household (and thus the number of potential earners).

\footnotetext{
${ }^{3}$ The averages are estimates based on the weighted average category of income in each group. By category the
} averages are: youngest group 5.89, pre-elderly 5.12, and elderly 3.03 . 
The youngest group in the study also purchased the most expensive houses on average $(\$ 246,669)$, followed by the pre-elderly $(\$ 218,072)$ and the elderly $(\$ 179,552)$. The minimum and maximum house prices also show the closer relationship between the young and the pre-elderly than with the elderly: young minimum $\$ 66,000$ and maximum $\$ 755,000$; preelderly minimum $\$ 63,000$ and maximum $\$ 775,000$; elderly minimum $\$ 43,000$ and maximum $\$ 465,000$. The price-to-income ratios provide another connection between the two younger groups: members of both groups spent roughly 2.5 times their annual income on their new homes ( 2.52 for the young, 2.65 for the pre-elderly). The elderly households spent nearly 4.5 times their income (4.42), indicating the likelihood of a large downpayment derived from equity built up in their previous homes.

The average importance that each age group attaches to the different reasons for choosing the new home and neighborhood are listed in the next several tables. The variables are divided into three groups: reasons for choosing the current house, reasons for choosing the current neighborhood, and accessibility-related reasons, shown in Tables 3, 4, and 5 respectively. Recall that the importance of each reason is measured on a seven-point Likert scale from "very unimportant" (1) to "very important" (7).

Where the age groups differed in average importance of reasons for their choices, the differences support our hypotheses. Relating to reasons for choosing the current residence (Table 3 ), the youngest group of households rate wanting a larger home as significantly more important than the other two groups, while the older a respondent, the more likely that wanting a smaller home was important. The youngest groups also were more likely to want a larger yard. The older two groups reported that desire for accessibility features in the home (things like no stairs or wide doorways) and ease of maintenance were more important.

The youngest group, as expected, was significantly more concerned about reputation of schools, amount of traffic in the neighborhood and amount of parks and open space (see Table 4). These make sense given the large proportion of these households with children. The older two groups showed less interest in these characteristics, whereas the elderly group was more concerned about quality of local garbage collection and local police services.

Among accessibility-related reasons (Table 5), the importance of distance to work declined steadily with increasing age, as expected. Distance to community recreational opportunities was more important to the youngest group than to either of the others. The pre-elderly were more like the youngest group in their concern with a move that would decrease their commuting cost and one that would decrease the traffic congestion on their commute. In general it appears that accessibility is not very important to respondents of any age in choosing a new home location, with the single exception of distance to work for the youngest age group. On average for this group distance to work rates as slightly more important than neutral (4.0), but not at the same level as factors related to the size, cost or investment value of the house or the quality of schools, traffic and safety in the neighborhood.

In addition to the differences between groups, certain variables were shown to be relatively important to all three groups (with no significant differences). These include size, cost and good investment or resale value of the house as well as the economic characteristics, safety, and general appearance of the neighborhood. Other factors were not very important, on average, to any of the age groups; these include the desire for an older home or a more expensive home, lower local income taxes and some accessibility variables including ability to walk to stores and services and availability of public transit. 
Table 3: $t$-test results of reasons for leaving current residences (standard deviations in parentheses).

\begin{tabular}{lrrr}
\hline Variables & Younger & Pre-elderly & Elderly \\
\hline Age of the house & $4.53(1.68)$ & $4.23(2.18)$ & $4.44(2.52)$ \\
Wanted a newer house & $3.15(2.16)$ & $2.84(2.42)$ & $3.09(2.49)$ \\
Wanted an older house & $2.14(1.63)$ & $1.82(1.63)$ & $1.55(1.42)$ \\
Size of the house & $6.08(1.20)$ & $5.99(1.18)$ & $6.03(1.80)$ \\
Wanted a larger home & $\mathbf{5 . 4 1}(2.11)$ & $3.12(2.44)$ & $\mathbf{1 . 9 2}(2.03)$ \\
Wanted a smaller home & $\mathbf{1 . 5 7}(1.45)$ & $3.16(2.54)$ & $\mathbf{4 . 8 0}(2.83)$ \\
Cost of the house & $6.10(1.12)$ & $6.06(1.27)$ & $5.69(1.76)$ \\
Wanted a more expensive home & $\mathbf{2 . 9 0}(1.93)$ & $1.97(1.78)$ & $1.50(1.37)$ \\
Wanted a less expensive home & $\mathbf{2 . 0 0}(1.67)$ & $2.61(2.36)$ & $2.95(2.78)$ \\
House has larger yard & $\mathbf{4 . 8 7}(1.97)$ & $3.12(2.31)$ & $\mathbf{1 . 9 5}(1.89)$ \\
House has smaller yard & $\mathbf{1 . 9 9}(1.62)$ & $3.01(2.46)$ & $3.86(2.73)$ \\
Quality of landscaping & $\mathbf{3 . 7 0}(1.76)$ & $4.11(2.05)$ & $4.28(2.10)$ \\
Yard has mature trees & $4.29(2.01)$ & $4.09(2.19)$ & $\mathbf{2 . 7 6}(2.42)$ \\
House has accessibility features* & $\mathbf{2 . 0 4}(1.74)$ & $3.86(2.73)$ & $\mathbf{5 . 5 2}(2.36)$ \\
Good investment or resale value & $5.73(1.40)$ & $5.71(1.75)$ & $\mathbf{5 . 2 8}(1.73)$ \\
Ease of maintenance of house & $\mathbf{4 . 3 0}(1.86)$ & $5.63(1.73)$ & $5.73(1.87)$ \\
Better energy efficiency & $\mathbf{3 . 7 1}(1.82)$ & $4.36(2.11)$ & $4.70(2.49)$ \\
\hline Bold indigtes &
\end{tabular}

Bold indicates significance at the 0.05 level in the $t$-test with the pre-elderly.

* e.g., no stairs, lower counters, etc.

\section{Discriminant Analysis}

It is clear that the different ages of respondents are related to their different household characteristics. In order to see the degree to which the respondents' reasons for purchasing their new homes (controlling for other household characteristics) can distinguish among the three age groups, a multiple discriminant analysis using the variables in Tables 3 through 5 was used to distinguish between the three groups. ${ }^{4}$

Discriminant analysis is a regression-related technique in which the researcher uses a set of nominal, ordinal, and interval variables as independent or predictor variables and estimates a model to distinguish between the categories of a nominal dependent variable (Klecka 1980). A stepwise model is a common first step in discriminant analysis (SAS Institute Inc. 2004). The second step is then to recalculate the model with only those variables significant in the stepwise calculations (Klecka 1980). This was the procedure used in this research; only the results of the final model are reported.

Discriminant analysis employs many of the same assumptions as linear regression, and this is one of the reasons why logistic regression is preferred in a case of two categories in the depen-

\footnotetext{
${ }^{4}$ Presence of school-aged children and whether a respondent was widowed had to be deleted from the model because the elderly group had no instances of the former characteristic and the younger group had no instances of the latter characteristic.

${ }^{5}$ The full set of analyses are available from the authors. Weighted values are as follows. $\mathrm{N}=448$; Total Frequency: Younger People $=263$, Pre-Elderly $=111$, Elderly $=47$
} 
Table 4: $t$-test results of reasons for choosing current neighborhoods (standard deviations in parentheses).

\begin{tabular}{lrrr}
\hline Variables & Younger & Pre-elderly & Elderly \\
\hline Reputation of schools & $\mathbf{5 . 0 9}(2.19)$ & $3.23(2.41)$ & $2.97(2.58)$ \\
Traffic in the neighborhood & $5.13(1.63)$ & $4.37(2.00)$ & $4.32(2.17)$ \\
Economic characteristics of the neighbor- & $5.18(1.55)$ & $5.01(1.92)$ & $5.06(1.81)$ \\
hood & & & \\
Racial composition of the neighborhood & $3.33(1.76)$ & $3.23(2.10)$ & $3.22(2.35)$ \\
Safety of the neighborhood & $5.81(1.33)$ & $5.66(1.70)$ & $5.85(2.17)$ \\
Property taxes & $4.23(1.60)$ & $4.24(1.92)$ & $4.68(2.14)$ \\
Lower local income taxes & $2.61(1.73)$ & $2.63(2.01)$ & $2.91(2.51)$ \\
Quality of local garbage collection & $3.35(1.76)$ & $3.30(1.99)$ & $4.25(2.53)$ \\
Quality of local police services & $4.25(1.88)$ & $4.72(2.08)$ & $5.09(2.20)$ \\
Quality of local road maintenance & $4.00(1.85)$ & $4.33(2.05)$ & $4.51(2.57)$ \\
The amount of parks and open space & $4.03(1.94)$ & $3.33(2.06)$ & $3.00(2.19)$ \\
General appearance of neighborhood & $5.78(1.32)$ & $5.58(1.83)$ & $5.72(1.84)$ \\
\hline
\end{tabular}

Bold indicates significance at the 0.05 level in the $t$-test with the pre-elderly.

dent variable. However, with three categories of people who do not have a choice about which category they fall into (unlike the situation involved in choosing among transportation modes, for example), multiple discriminant analysis is the preferred technique. Fortunately, there is significant evidence that discriminant analysis is a relatively robust technique even when its assumptions are not completely met (Klecka 1980; Lachenbruch 1975). Klecka (1980) suggests that the best check on the impact of violations of the assumptions is an examination of the percentage correctly classified by the estimated model; if this percentage is relatively high, the violation of the assumptions was probably minor, though results should still be interpreted with caution. The percentage correctly classified is considered in the discussion of the results of the discriminant analysis.

Tables 6 and 7 present the results of this effort to distinguish among these three age groups. Multiple discriminant analysis produces discriminant functions to distinguish among the groups. It produces one fewer function than there are groups, but only those that are statistically significant are used in the analysis. In this case, the two functions (for three groups) are both significant and are discussed below. Each group's cases are used to calculate a mean for that group on each function and these are listed in Table 6. On Function 1, the two older groups have negative means and the youngest group has a positive mean, indicating that this function will best distinguish between the young and the other two groups. The means on Function 2 indicates that it will be better at distinguishing the two older groups from each other (the oldest group's mean is negative and the pre-elderly mean is positive).

Table 7 lists the coefficients from the discriminant functions. Note that the analysis indicates which variables distinguish among the age groups based on the self-reported importance of each independent variable (and on income, the only household characteristic that distinguished among the groups). Thus, a variable that is not significant may have been very important to all three groups, not important at all to all three groups or moderately important to 
Table 5: $t$-test results of accessibility-related measures (standard deviations in parentheses).

\begin{tabular}{lrrr}
\hline Variables & Younger & Pre-elderly & Elderly \\
\hline Distance to work & $\mathbf{4 . 0 4}(2.04)$ & $3.23(2.23)$ & $\mathbf{1 . 3 8}(1.47)$ \\
Distance to family and/or friends & $3.86(2.00)$ & $3.81(2.27)$ & $3.63(2.78)$ \\
Wanted to be closer to more desirable shop- & $2.83(1.75)$ & $2.66(1.86)$ & $3.04(2.46)$ \\
ping areas & & & \\
Community recreational opportunities & $3.62(1.90)$ & $2.83(1.93)$ & $2.81(2.21)$ \\
Decreased my commuting cost & $2.56(1.86)$ & $2.46(2.00)$ & $\mathbf{1 . 3 3}(1.24)$ \\
Less traffic congestion on my new commute & $2.70(1.88)$ & $2.79(2.13)$ & $\mathbf{1 . 3 0}(1.13)$ \\
Availability of public transit & $1.87(1.43)$ & $1.61(1.31)$ & $2.22(2.16)$ \\
Ability to walk to stores and services & $2.69(2.02)$ & $2.58(2.01)$ & $2.48(2.41)$ \\
\hline
\end{tabular}

Bold indicates significance at the 0.05 level in the $t$-test with the pre-elderly.

all three groups-but the groups did not differ significantly in the importance they assigned to the item. The majority of the characteristics of the house, the neighborhood, and access to different destinations proved to be equally important, on average, to all three groups; that is, these characteristics do not appear in the discriminant functions because their coefficients were insignificant. These include items known to rank relatively high, such as size of the house, good investment or resale value, safety of the neighborhood, economic characteristics of the neighborbood, and general appearance of the neighborhood. They also include items that ranked relatively low for all groups, such as lower local income taxes and ability to walk to stores and services.

Table 6: Means of the discriminant functions.

\begin{tabular}{lrr}
\hline & Function 1 & Function 2 \\
\hline Younger & 0.8739 & -0.1206 \\
Pre-Elderly & -0.9348 & 0.5792 \\
Elderly & -2.6909 & -0.6978 \\
\hline
\end{tabular}

Function 1 in Table 7 indicates those items that differentiate the young from the other two groups (holding the other variables constant). Items more important to the youngest group include wanting a larger house, distance to work, reputation of schools, a house with a larger yard, availability of public transit, and cost of the house. Income also differentiated this group from the older groups, with the youngest group having the highest incomes. Note that the model is standardized so the coefficients can be compared to each other. Thus the most important item is distance to work. This supports the hypothesis that accessibility of work places would be an important issue for the youngest group of home buyers, and explains why some previous researchers have found this to be a continuing factor in home buyer decisions while others have not. This finding also supports an argument for mobility studies that subdivide the population into meaningful groups.

Variables that were more important to the combined older group include house has accessibility features such as no stairs or wide doorways (the most important), ease of maintenance 
Table 7: Standardized canonical discriminant function coefficients.

\begin{tabular}{lrr}
\hline Variable & Function 1 & Function 2 \\
\hline Wanted a larger home & 0.4266 & -0.3338 \\
House has accessibility features & -0.4513 & -0.111 \\
Distance to work & 0.5169 & 0.2217 \\
Reputation of schools & 0.3151 & -0.2621 \\
Income & 0.2563 & 0.4743 \\
Ease of maintenance of house & -0.0345 & 0.4677 \\
Quality of local garbage collection & -0.1478 & -0.4208 \\
House has larger yard & 0.3331 & 0.0992 \\
Quality of landscaping & -0.0736 & 0.4916 \\
Availability of public transit & 0.1303 & -0.2868 \\
Cost of the house & 0.2185 & 0.1386 \\
Quality of local police service & -0.2892 & 0.1818 \\
\hline Adjusted Canonical Correlation & 0.7652 & 0.3323 \\
Approximate F Value & 24.03 & 5.67 \\
Degrees of Freedom (N/D) & $24 / 840$ & $11 / 421$ \\
Pr>F & $<0.0001$ & $<0.0001$ \\
\hline
\end{tabular}

(the least important to the combined older groups), quality of local garbage collection, quality of landscaping and quality of local police services.

Function 2 is most useful for distinguishing the pre-elderly (positive mean on the function) from the elderly (negative mean on the function). This function should be interpreted cautiously because of the relatively small sample size of the elderly group. Nonetheless, there are some interesting results. The elderly were more interested (all other things equal) in a larger home with accessibility features (the accessibility features in the house were the least important items in the model), school reputation, quality of local garbage collection (most important) and availability of public transit. It is particularly interesting that the youngest (in Function 1) and oldest (in Function 2) groups are more interested than the pre-elderly in public transit. Some of the young may use transit for commuting purposes-its coefficient was significant, but not high for them. The elderly had a higher coefficient on this reason for home choice and it clearly is more important for them than for the pre-elderly, perhaps indicating an issue that becomes more important with age. Public transit service in the study area is mainly provided by fixedroute bus service. In 2000, the local transit system generated 48.88 passenger miles per capita (Wendell Cox Consultancy 2002). Local non transit commuting times are relatively short (averaging 22.9 minutes in 2000) and transit commuters average 55 percent longer transit times at 35.6 minutes (Wendell Cox Consultancy 2002). Fares for seniors are reduced and passengers with an ADA identification ride free (Central Ohio Transit Authority 2008), so transit may be relatively affordable for the oldest group in our study.

Local garbage service is another interesting item of importance to elderly people. Perhaps the elderly are interested in services that save them from having to move heavy trash barrels to and from the street. If so, communities may need to consider this aspect of serving the older population. 
Function 2 indicates that the pre-elderly are different from the elderly in their concern with distance to work, ease of home maintenance, desire for a larger yard (least important), quality of landscaping (most important), cost of the house and quality of local police services. Quality of landscaping, larger yard and cost of the house may relate to the house as a symbol of social status, as discussed earlier. The pre-elderly are also distinguished from the elderly by higher incomes. People in this age group are at the peak of their earnings, in many cases their children are gone and they are choosing a new home to conform to the lifestyle they want to have (or, at least, to project).

One way to judge the quality of a discriminant analysis is to create a classification matrix by using the model to classify all the cases and then tallying how often the classification was correct. As noted earlier, Klecka (1980) indicates that the percentage correctly classified is a reasonable check on whether researchers should be concerned about violations of the technique's assumptions. Using the same data to derive the function and also to test the classification will lead to some inflation in the percentage correctly classified. Nonetheless, one can examine the percentage correctly classified to see if it is greater than would be expected with random assignment to categories based on the actual size of the groups.

Overall, $75 \%$ of the cases were correctly classified. The weighted proportion correct in a proportional random assignment of cases would be $61 \%$. Thus, the discriminant analysis adds to our ability to distinguish between the groups. The classification functions correctly classified 85.36 percent of the youngest group, 58.62 percent of the pre-elderly and 78.95 percent of the elderly. It is interesting to note that the function was more successful in categorizing the youngest and oldest groups and somewhat less so in the case of the pre-elderly. When the preelderly were misclassified, they were more likely to be misclassified as part of the younger group (24.14\%) than the older group (17.24\%). When the young group was misclassified it was almost always as pre-elderly rather than elderly ( $13.93 \%$ as opposed to $0.71 \%)$. When the elderly were misclassified they were split evenly between the other two groups (10.53\% to each). This supports our earlier finding that the pre-elderly are sometimes more like the younger age group and sometimes more like the elders.

\section{Discussion and Conclusions}

This research set out to discover whether the pre-elderly make different residential location decisions for different reasons than the other two age groups and to explore the determinants of these residential location decisions.The pre-elderly are defined here as early baby boomers who were between the ages of 50 and 64 (inclusive) in 2006. We were particularly interested in situating this group in terms of the literature on the impact of life course position and the importance of locations with good accessibility, measured in several ways. Comparisons of preelderly home buyers to younger home buyers and elderly home buyers have largely supported initial expectations-with some interesting exceptions.

The three groups share a general tendency to purchase homes in the suburbs or the suburban parts of the city of Columbus (with the downtown exception mentioned earlier). Figure 1 indicates some differences (likely related to presence of children) and the potential for the city of Columbus to be able to attract the pre-elderly and perhaps the childless part of the youngest group. The most important reasons for selecting the current home for all groups related to size and cost of the house, good investment or resale value and the appearance, economic characteris- 
tics and safety of the neighborhood. Accessibility issues are not especially important except that the youngest group was more interested in distance to work when they purchased their current homes.

Communities interested in attracting or accommodating the pre-elderly age group do not need to worry too much about school quality. However the size and cost of housing remain quite important to this group, and the importance of ease of maintenance to the home purchase is also a crucial factor that differentiates them from the other two age groups when they move. Given the size of this cohort and its housing preferences (at least as seen in our data), it is unlikely that the current housing stock will meet its needs. Thus new developments (or redevelopments) might focus on condominium situations where exterior maintenance is included and the relatively higher density decreases the cost per unit. Lower property taxes can be an asset in attracting this group as well and could be easier to achieve because the pre-elderly are less interested than other groups in school quality. The youngest group, in particular, may want lower taxes, but will need to accept a higher tax rate in order to obtain the good school quality that it rates as very important.

The housing life-course literature focuses on issues such as the different roles that people take on at different points in life, the transitions between life stages, and the duration of certain roles (Wenning 1995). In light of those points, the role of parent has important implications for residential mobility, and the transition out of parenthood as children leave the nest opens up other possibilities for some people. The results of this research indicate some of the differences between the youngest group (most of those with school aged children present in this sample) and those who have moved to the next life state, the pre-elderly. However, this research has also shown the pre-elderly share some characteristics with the youngest group of home buyers in that they have relatively high incomes, and their housing choices are characterized by similar house prices and price-to-income ratios.

The expectation of the role of "elder with the possibility of physical problems" may lead people in the pre-elderly group to look for housing with more accessibility features and lower maintenance requirements. The pre-elderly are more like the elderly in that they have relatively little concern for school quality (in fact, discriminant analysis indicates that the elderly care more about school quality than the pre-elderly) or other issues that might relate to children. In addition both groups are interested in owning homes with accessibility features, though the pre-elderly group has significantly higher incomes and pays more for homes, on average.

Interestingly, the possibility of being unable to drive seems to enter the picture for the elderly but not for the pre-elderly (as evidenced by interest in availability of public transit). However, neither group shows much attention to having shops and services within walking distance. This attention to public transit may indicate the duration of stay that people expect in the home they just purchased. The elderly may already need transit or may expect to remain in the home long enough that they will eventually rely on it. The pre-elderly may expect to move again or to be able to avoid health issues that will force them to stop driving. The people studied in this research have recently moved, so they may expect to move again as their life situation changes. The pre-elderly result may also reflect the very high value placed on personal automobiles in the U.S.; people may be willing to consider some physical diminishment of their abilities, but it appears that most are not thinking about the possibility that they will be unable to drive.

The pre-elderly also have a distinct set of concerns of their own based around lifestyle issues, as illustrated by their stronger interest in ease of maintenance of their new homes. Their 
smaller household sizes, fewer constraints due to children at home, and relatively large incomes free them to pursue interests outside their homes and this is reflected in a desire to avoid maintenance. Discriminant analysis showed that the importance of wanting larger yards and quality landscaping differentiates this group from the others. These variables might be related to status. The quality of the local police services relates to crime issues, but also to status and possibly to creating a comfortable context for more travel (feeling that the home is safe because of the good community policing).

The results of our analyses indicate that while the pre-elderly in the United States share various characteristics with one or the other (or both) of the other groups, they are a niche market of their own. Communities might be interested in targeting this group because of its relative wealth and low demands on local services. This age group purchases relatively high-end housing and they are differentiated from the other age groups by the importance of easy-care housing and high-quality landscaping. They are looking for lifestyle amenities, but our survey results do not allow us to say exactly what those amenities are. For some, the amenity may be the "fountain of youth" of urban living, as Ezell (2006) argues. For others, important amenities may include a new suburban estate with all yard care hired out or a beautifully landscaped golf course community where the homeowners' association takes care of all maintenance. These are among the details that need further research. Others include the group's expectations about future mobility, the role of transportation for an aging population, and the extent to which the pre-elderly group's higher income will persist into its retirement years. In addition, all three age groups should be disaggregated in additional ways (e.g. by income, race, and location) to gain more understanding of the different subgroups within these categories. Whatever such research might show about the different portions of the pre-elderly group, it is an important submarket that differs in significant ways from both younger and older home buyers. It will be interesting to follow their movement into the retirement years to see how their new life roles affect their choices and to track the implications of those choices for a host of issues ranging from community development to housing markets to transportation.

\section{References}

Alonso, W. 1964. Location and Land Use. Harvard University Press.

Bures, R. M. 1997. Migration and the life course: Is there a retirement transition? International Journal of Population Geography 3: 109-119. doi:10.1002/(SICI)1099-1220(199706)3: $2<109:: A I D-I J P G 65>3.0 . C O ; 2-$ I.

Central Ohio Transit Authority. 2008. Fares and passes. COTA, columbus, OH. URL http: //www.cota.com/fares_and_passes.asp.

Clark, D., T. Knapp, and N. White. 1996. Personal and location-specific characteristics and elderly interstate migration. Growth and Change 27: 327-351. doi:10.1111/j.1468-2257. 1996.tb00909.x.

Cropper, M. and P. Gordon. 1991. Wasteful commuting: a re-examination. Journal of Urban Economics 29 (1): 2-13. URL http://ideas.repec.org/a/eee/juecon/v29y1991ilp2-13.html. Ezell, K. 2006. Retire Downtown; the Lifestyle Destination for Active Retirees and Empty Nesters. Filion, P., T. Bunting, and K. Warriner. 1999. The entrenchment of urban dispersion: Residential preferences and location patterns in the dispersed city. Urban Studies 36: 1317-1347. doi:10.1080/0042098993015. 
Giuliano, G. and K. A. Small. 1993. Is the journey to work explained by urban structure? Urban Studies 30 (9): 1485-1500. doi:10.1080/00420989320081461.

Hamilton, B. and A. Röell. 1982. Wasteful commuting. Journal of Political Economy 90 (5): 1035-1053. URL http://www.jstor.org/stable/1837132.

Kim, M. J. and H. A. Morrow-Jones. 2005. Current determinants of residential location decisions. In D. M. Levinson and K. J. Krizek, eds., Access to Destinations, 149-170. Elsevier.

Klecka, W. R. 1980. Discriminant Analysis. Number 19 in Sage Quantitative Applications in the Social Sciences. Sage Publications.

Krizek, K. J. and P. Waddell. 2003. Analysis of lifestyle choices: Neighborhood type, travel patterns, and activity participation. Transportation Research Record 1807: 119-128. doi: 10.3141/1807-15.

Lachenbruch, P. 1975. Discriminant Analysis. New York: Hafner.

Levine, J. 1998. Rethinking accessibility and job-housing balance. Journal of the American Planning Association 64: 133-149.

Masnick, G. 2003. The new demographics of housing. Housing Policy Debate 13 (2): 275-321. URL http://www.mi.vt.edu/data/files/hpd\%2013(2)/hpd\%2013(2)_masnick.pdf.

Mills, E. S. 1967. An aggregative model of resource allocation in a metropolitan area. American Economic Review 57: 197-210. URL http://www.jstor.org/stable/1821621.

Morrow-Jones, H. and M. V. Wenning. 2005. The housing ladder, the housing life cycle and the housing life course: Upward and downward movement among repeat homebuyers in a metropolitan housing market. Urban Studies 42: 1739-1754. doi:10.1080/ 00420980500231647.

Muth, R. F. 1969. Cities and Housing. University of Chicago Press.

Myers, D. 2000. Building the future as a process in time. In Lincoln Institute of Land Policy Annual Roundtable: Metropolitan Development Patterns. Cambridge, MA. URL http:// www-rcf.usc.edu/ dowell/pdf/buildingthefuture.pdf.

OHRN. 1994. Moving Up and Out: Government Policy and The Future of Ohio's Metropolitan Area. Technical report, The Ohio Housing Research Network, The Ohio Urban University Program.

Rowles, G. D. 1993. Evolving images of place in aging and 'aging in place'. Generations 17: 65. SAS Institute Inc. 2004. SAS OnlineDoc 9.1.3. SAS Institute, Inc., Cary NC.

Walters, W. H. 2002. Later-life migration in the United States: A review of recent research. Journal of Planning Literature 17: 37-66. doi:10.1177/088541220201700103.

Weisbrod, G., S. Lerman, and M. Ben-Akiva. 1980. Tradeoffs in residential location decisions: Transportation versus other factors. Transport Policy and Decision Making 1: 13-26.

Wendell Cox Consultancy. 2002. Urban transport fact books. URL http://www. publicpurpose.com/tfb-ix.htm.

Wenning, M. V. 1995. Rethinking the link: Residential mobility, housing and the life cycle. In City and Regional Planning. The Ohio State University. 